\title{
BMJ Open Participation of young children with developmental disabilities: parental needs and strategies, a qualitative thematic analysis
}

\author{
Marieke Coussens (D , ${ }^{1}$ Floris Vitse, ${ }^{1}$ Annemie Desoete, ${ }^{2}$ Guy Vanderstraeten, ${ }^{1}$ \\ Hilde Van Waelvelde, ${ }^{1}$ Dominique Van de Velde (D) ${ }^{1}$
}

To cite: Coussens $M$, Vitse F, Desoete A, et al. Participation of young children with developmental disabilities: parental needs and strategies, a qualitative thematic analysis. BMJ Open 2021;11:e042732. doi:10.1136/ bmjopen-2020-042732

- Prepublication history and additional material for this paper are available online. To view these files, please visit the journal online (http://dx.doi org/10.1136/bmjopen-2020042732).

Received 06 August 2020 Revised 17 February 2021 Accepted 09 March 2021

Check for updates

(C) Author(s) (or their employer(s)) 2021. Re-use permitted under CC BY-NC. No commercial re-use. See rights and permissions. Published by BMJ.

${ }^{1}$ Faculty of Medicine and Health Sciences, Department of Rehabilitation Science, Ghent University, Ghent, Belgium

${ }^{2}$ Faculty of Psychology and Educational Sciences, Ghent University, Gent, Belgium

Correspondence to Dr Marieke Coussens; marieke.coussens@ugent.be

\section{ABSTRACT}

Objectives Participation refers to a person's involvement in activities and roles that provide interaction with others as well as engagement in family and community activities. Young children with developmental disabilities (DD) such as attention deficit hyperactive disorder, autism spectrum disorder and developmental coordination disorder are limited in their participation compared with their typically developing peers. This study aimed to obtain information regarding parental needs and strategies used to enable their child's participation.

Design A thematic inductive approach with in-depth interviews was used to explore parental experiences. Eleven women and two men, between 30 and 40 years of age, who had a child (4-9 years old) with a DD diagnosis based on Diagnostic and Statistical Manual of Mental Disorders criteria, participated in semistructured interviews.

Results Two central themes emerged: parental needs and parental strategies used to enable their child's participation. Parental needs were the following: increasing awareness, ameliorating parental burden, providing tailored interventions and supporting parents in finding suitable leisure activities. Parental strategies aimed at increasing their child's resiliency, attaining maximal fit between activity requirements and child capacity, and creating inclusive opportunities and awareness.

Conclusions Understanding what families' needs are and how families use and integrate strategies within the context of their daily lives provides practitioners with insights needed to support families' resiliency in promoting their children's participation. The results have implications for professionals as this information can be used to inform refine, or tailor participation-based and family-centred services.

\section{INTRODUCTION}

The Diagnostic and Statistical Manual of Mental Disorders Fifth Edition (DSM-5) categorises developmental disabilities (DD), such as attention deficit hyperactive disorder (ADHD), autism spectrum disorder (ASD), and/or developmental coordination disorder (DCD), as 'hidden' lifelong neurobiological
Strengths and limitations of this study

- The strength of the study is that this is one of the first studies tapping in depth into the needs parents had and into strategies that parents of young children with developmental disabilities (DD) used to enable their child's participation.

- Additional research is needed on non-Flemishspeaking parents with a larger sample of parents with different educational backgrounds.

- Even though this study identified the range and scope of strategies that parents used to facilitate their child's participation, the effectiveness of those strategies was not assessed.

- The results can be used as a starting point for further investigation into family experiences regarding the participation of young children with DD. The results of this study are only applicable to similar groups of highly educated parents with children with $\mathrm{DD}$ and cannot be transferred beyond this group. The results, however, provide us insight into how to use this new knowledge in designing participation-focused intervention programmes for children with DD and their parents, but further research is necessary.

developmental disorders with high rates of comorbidity. ${ }^{1}$ With a prevalence of $5 \%-6 \%$, ADHD, ASD and DCD are some of the most common disorders affecting school-aged children. ${ }^{1}$

ADHD, DCD and ASD are DD that normally have their onset in early childhood. Diagnoses such as ADHD, DCD and ASD frequently co-occur. ${ }^{12}$ Recent studies suggest that about $50 \%$ of children diagnosed with DD have an additional comorbid disorder, ${ }^{3}$ pointing to multiple deficits and a potential link between these disabilities. ${ }^{2}{ }^{4}$ When ADHD, DCD or ASD co-occurs, the outcome tends to be more severe than in isolated disabilities, ${ }^{5}$ with poorer psychosocial outcomes and higher levels of depressive symptoms in children with comorbid disabilities. ${ }^{6}$ Children with DD 
are most restricted in active recreation and community socialisation activities and have less variety and tempo in their daily lives than children without disabilities. ${ }^{7-11}$ Research also indicates that children with DD are limited in their participation compared with their typically developing peers. ${ }^{8912}$

According to the $\mathrm{WHO},{ }^{13}$ participation can be described as 'involvement in a life situation'. Participation refers to a child's involvement in activities and roles that provide ${ }^{14}$ interaction with others as well as engagement in family and community activities. ${ }^{115}$

Participation includes any activity at home, school/ daycare and in the community (eg, playing at home, playing on a sports team or attending social outings with friends). Participation is important for leading a healthy and satisfying life. ${ }^{1617}$

It is a multidimensional concept that is influenced by personal factors related to the children and families and also by environmental factors. ${ }^{18-20}$

According to the family of participation-related constructs (fPRC), participation includes two essential concepts: attendance at an activity and a level of involvement. ${ }^{19-23}$ Attendance is defined as 'being there' and is measured by the frequency and/or diversity of activities in which the person takes part. Involvement is outlined as the experience of participation while attending, including elements of motivation, persistence, social connection and affect p.6 ${ }^{2}{ }^{21}$ By conceptualising preferences as a precursor to participation and participation as containing two dimensions (attendance and involvement), two key outputs can be outlined, more specifically activity competence and sense of self. According to the fPRC, these outputs influence future participation and therefore display a cyclic nature. The fPRC also outlines the external factors that influence participation, including the environment and how available, accessible, affordable, accommodating and acceptable opportunities are for individuals experiencing disabilities. ${ }^{21}$ The fPRC proposes a more detailed understanding of the participation construct that involves transactional exchanges among multiple intrinsic and extrinsic elements over time and its relationship with the intrinsic elements of the person (activity competence, sense of self and preferences), the activity setting or context, and the broader environment. The fPRC by Imms $e t a l^{19-21} 24$ was used for this research study, as this definition of participation could be applied to any activity or setting, regardless of the ability of the children with DD. ${ }^{18}$ Also, by using the fPRC as a guiding framework, this research has the potential to empower and permit clarity throughout future participation-focused work. ${ }^{3}$

According to the $\mathrm{WHO},{ }^{13}$ restrictions to participation can occur due to child factors, considering his or her capacity to perform a task, or factors related to the physical and social environment that influence performance, that is, what the child does in a natural context. ${ }^{25}$ Research has also indicated that all children's participation is influenced by age, sex and income. ${ }^{25-30}$
Among children with disabilities, the severity of their condition as well as their functional abilities are also known to influence changes in participation over time. ${ }^{31-33}$ This evidence is even more apparent as children with disabilities get older. Results show that levels of participation decrease as children grow up, especially during the transition into adolescence ${ }^{34-36}$ Likewise, with accumulating knowledge, it is clear that the environment is inextricably linked to participation. ${ }^{18}{ }^{30}$ In other words, the nature and extent of participation of children with DD are influenced by a number of child, family and environmental factors.

According to Imms et $a l^{21}$ recent emphasis has been placed on the environment in supporting the participation of young children with DD in relevant life situations. There is evidence that levels of participation decrease as children grow up, especially during the transition into adolescence. $^{18}{ }^{37-39}$ Child characteristics (namely child functioning, the presence of disability, functional limitations or complexity of the child's conditioning) had an indirect effect on participation in home, school or community activities. Parents of preschool children with physical disabilities and special needs identified more environmental barriers and fewer environmental supports at home and in the community. ${ }^{10} 253040-42$ Barriers identified by these parents were related to the physical design of homes and the community, family resources, social attitudes, assistance and supports outside of the home, transportation, and assistive devices or equipment. ${ }^{10}{ }^{41}$ This evidence suggests that specific environmental factors are modified and are considered a major target of intervention to promote child participation and functioning. ${ }^{10} 18303839$ However, little information is available related to whether similar environmental barriers are perceived with respect to the participation of young children with more invisible disabilities such as ASD, ADHD and/or DCD. This information, however, can guide professionals to alter or use specific environmental modifications as a target of intervention to enable the participation of young children with more invisible DD.

Furthermore, Shonkoff and Phillips ${ }^{43}$ have shown that there has been an explosion of research in the neurobiological, behavioural, and social sciences that has led to major advances in understanding the conditions that influence whether children get off to a promising or a worrisome start in life. More specifically, if children with disabilities can get the right amount of support at an early stage in life, their prognosis can be better, as secondary problems due to the disability can be overcome. It is therefore especially indispensable to obtain more knowledge on the participation of young children, as the research by Shonkoff and Phillips ${ }^{43}$ shows that the preschool years are the period in which children first start to learn their roles within a group, gain new skills and practise these skills in their environments. ${ }^{43}$ In addition, participation throughout the preschool years highly depends on the opportunities provided to children by the adults in their everyday environment, typically their 
parents or caregivers. ${ }^{7}$ The current literature indicates that children with disabilities participate less frequently in domestic, educational, leisure and social activities when we compare them with their typically developing peers. ${ }^{43-45}$ Redirecting the focus to modifying the environment (family functioning, support and access to resources) should support intervention planning for very young children in collaboration with their families. ${ }^{21}$

In order to generate new strategies to enable young children with DD to participate as fully as they can and want to, more knowledge about the participation of young children with DD is needed. This is in order to develop practices that are the most efficacious. Practitioners and families are encouraged to provide inclusive and enriched learning environments that foster children's overall health and development in the community. ${ }^{40}$ Enhancing children's participation in activities in daily life is a main goal for all professionals working with young children. ${ }^{46}$ A family-centred framework that promotes children's participation in typical family and community activities and routines should be the foundation of early intervention services. ${ }^{47}$

Currently recommended practices reflect Bronfenbrenner's ecological perspectives of human learning and development where the family is recognised as the most proximal influence on children's development and learning. ${ }^{48}$ As a result, in early intervention, both the family as well as the children are viewed as the target of the services. Hence, the role of the professional is to support and provide families with knowledge, resources and strategies. This support helps caregivers to facilitate their children's participation and learning within typical activities and routines. ${ }^{49}$ To unravel the complexities of participation, figuring out what parental needs are, as well as the strategies they use to enable their young child's participation, seems indispensable. Since participation is associated with positive outcomes for all children, participation could have a more significant impact on the development of young children with DD since they are at risk of experiencing more participation-related problems compared with their age-matched peers without developmental problems. ${ }^{51-53}$

There seems to be a knowledge gap specifically concerning the needs and strategies used by parents of young children with DD. This knowledge gap results in less insight into disparities in participation during early childhood in order to guide intervention planning at an early point in the child's trajectory. ${ }^{54}$ Focusing on young children is important because children face a challenging transition from kindergarten to elementary school. It is a transitional stage during which lifelong habits can be established through positive experiences and opportunities for participation, capacity building and empowerment. ${ }^{55}$ Gathering a better understanding of how parents enable the participation of their children with DD through this transitional stage would help professionals since they can build on those strategies and through family-centred care can jointly promote participation.
Improving the lived experience of children with DD by optimising participation requires that professionals and families understand what influences participation and then carefully consider intervention choices.

Therefore, the purpose of the study was (1) to explore within the home, school/daycare or community setting the parental needs regarding enabling their young child's participation in daily activities, and (2) to investigate the scope of strategies used by parents of young children with DD in trying to improve their level of participation.

\section{METHODS \\ Design}

A thematic inductive approach with in-depth semistructured interviews was used to explore parental needs and strategies used to enable children's participation. Qualitative research is especially suited to the study of complex interactions, such as those between individuals and the environment. ${ }^{56}$ Further, qualitative methods are considered to be the most effective means of studying the lived experience; they provide the researcher with an opportunity to understand life experiences from the perspectives of the individual. ${ }^{57}$ We chose to use semistructured interviews, as opposed to unstructured interviews, as there were specific domains that we hoped to cover, and interviews are the preferred method for collecting data about people's thoughts, feelings and perceptions. ${ }^{589}$ An overview of the possible questions during the interview can be found in the online supplemental appendix 1 .

\section{Participants and recruitment}

Purposive sampling was used to recruit participants between January and June 2018 from the Flemishspeaking part of Belgium. Details regarding the study and our contact information were provided to possible participants (parents of young children with DD) via posting messages on Facebook and providing letters to support groups and agencies that render services to children with DD. Interested participants took the initiative to contact the researchers. After data collection, patterns were identified and analysed according to guidelines for thematic analyses by Braun and Clarke. ${ }^{60}$

Participants were included when they were Dutchspeaking parents with a child between 4 and 9 years of age with an official ADHD, and/or ASD and/or DCD diagnosis. To be eligible for the study, the parents had to have a child with a typical IQ for the age range between 4 and 9 years of age, who met the criteria for ADHD and/or DCD and/or ASD outlined in the DSM-5. ${ }^{1}$ Children with a typical IQ were recruited as we wanted to obtain information on how disabilities that are more invisible, such as ADHD and/or ASD and/or DCD, impact the participation of these children, without IQ being a confounding variable.

The IQ scores were calculated by the professionals from the recognised (by the government) diagnostic rehabilitation centres in Flanders using standardised assessments 


\begin{tabular}{|c|c|c|c|c|}
\hline Strategy & Methods & Data collection & Data analysis & Comment \\
\hline \multirow[t]{3}{*}{ Credibility } & $\begin{array}{l}\text { Triangulation } \\
\text { of different } \\
\text { researchers }\end{array}$ & - & $\sqrt{ }$ & Two researchers were involved in the data analysis. \\
\hline & Member checking & $\sqrt{ }$ & $\sqrt{ }$ & $\begin{array}{l}\text { Interview summaries were provided to all participants } \\
\text { during the data collection. A summary of emerging } \\
\text { themes was presented to all participants during the } \\
\text { data analysis. }\end{array}$ \\
\hline & Peer debriefing & - & $\sqrt{ }$ & Three researchers discussed the analysis of the data. \\
\hline Transferability & $\begin{array}{l}\text { Rich description of } \\
\text { participants }\end{array}$ & $\sqrt{ }$ & - & $\begin{array}{l}\text { In the first phase of the interview, demographic } \\
\text { information regarding the participants was collected. }\end{array}$ \\
\hline \multirow[t]{2}{*}{ Dependability } & $\begin{array}{l}\text { Dense description } \\
\text { of research } \\
\text { methods }\end{array}$ & $\sqrt{ }$ & - & $\begin{array}{l}\text { A detailed description of the methods was provided } \\
\text { for study replication. }\end{array}$ \\
\hline & & - & $\sqrt{ }$ & $\begin{array}{l}\text { The first and second researchers recoded } 1 \text { week } \\
\text { following initial coding. }\end{array}$ \\
\hline Confirmability & $\begin{array}{l}\text { Triangulation } \\
\text { of different } \\
\text { researchers }\end{array}$ & - & $\sqrt{ }$ & As above \\
\hline
\end{tabular}

such as the Wechsler Preschool and Primary Scale of Intelligence. ${ }^{61}$ Participants and their children's names were pseudonymised.

\section{Procedures}

After completing a written informed consent, demographic data of parents (eg, age, gender, employment status, country) and children (eg, age, gender, diagnosis, IQ scores received from the official rehabilitation centre and school placement) were collected. Parents completed one semistructured interview. Parents were given the choice to have the interview as a couple or as sole parent. Two researchers trained in qualitative interview methods conducted the interviews. An interview guide consisted of a grand tour of questions and probes and was constructed to gain an understanding of the parents' perceptions on enabling their child's participation (online supplemental appendix 1). The interview guide was not pilot tested. The purpose of using a grand tour question was to encourage participants to talk and elaborate on the topic of interest. Table 1 provides more information on the strategies used to establish rigour.

An important consideration in qualitative research is the issue of trustworthiness. Trustworthiness involves establishing credibility, transferability, dependability and conformability. ${ }^{62}$ In this study, credibility was established through the use of semistructured interviews and the completion of member checks to ensure the accuracy of the research results. Furthermore, we collected detailed descriptive information about the participants and their children to increase transferability. However, to ensure the privacy of the participants, we could not provide more information as this could lead to the recognition of the participants. We have tried to provide a general overview with the necessary details of the participants and their context in table 1. Detailed information was saved on our secured database and can only be accessed by the primary investigator. Also, analyst triangulation of two researchers, as described by Denzin and Lincoln ${ }^{62} 63$ was involved in the data analyses. Via constantly peer-debriefing our analysis with the research team, we ensured the credibility of the data. In addition, audits of the transcripts by two experienced researchers were completed to ensure the transcripts were accurate. Table 1 provides more information regarding the strategies used to establish rigour. After the interviews were transcribed verbatim, a copy was sent out to the participant.

Criteria for reporting qualitative research, which have been added as supplemental material in online supplemental appendix $2,{ }^{64}$ were followed to guide this research.

\section{Data analysis}

The first two researchers transcribed all audio-taped interviews verbatim, which were then cross-checked with the digital recording to ensure accuracy. Field notes were made. A first member check took place via sending the entire transcribed interview to the participant. A week later, the researchers called the participants to ask whether the participants approved or wanted to alter or add information. In a second member check, a synthesis of the preliminary results of all the participants was sent in an easy-to-read format. The first and the second authors analysed the data independently of one another, and the findings were constantly debriefed and discussed with the entire research team to find consensus. Data analysis was initiated as soon as an interview was completed and 
transcribed so that the first two researchers could analyse each interview to enhance credibility. The data analysis consisted of five phases following Braun and Clarke's ${ }^{60}$ thematic analysis guidelines.

Initial ideas were noted and shared with the first two researchers. All researchers contributed to the data analysis. The first researcher was an occupational therapist, who is acquainted with the literature on DD and participation and has extensive experience working with young children and families with DD. The second researcher was an occupational therapist with experience in working with children with DD and qualitative research. All the other researchers were senior researchers experienced in clinical work as well as in conducting research on DD. Our multidisciplinary team consisted of occupational therapists, a psychologist, a child neurologist, a rehabilitation doctor and a physiotherapist. The research team had no connection with the children, their families and their clinicians. First, codes were generated based on the words spoken by the parents. Second, codes with a similar semantic meaning were grouped together. Third, the codes were grouped together according to themes based on explicit or surface meanings rather than interpretation.

Analysis was completed using NVivo V.12 with qualitative data analysis software. ${ }^{65}$ During peer-debriefing sessions between the first, second and last authors, the researchers generated a uniform body of interwoven themes, resulting in a thematic map of them and their relationships. Potential themes were then checked by the entire research team and provided to the parents to see whether the themes expressed their experiences in relation to the research question, thereby resulting in a thematic map.

\section{Patient and public involvement}

Neither patients nor the public were involved in the development of the research design, nor in the conduct, reporting, or dissemination plans of our research.

\section{RESULTS \\ Participants}

Seventeen families contacted the researchers via email or a Google docs form, stating that they were interested in participating in the study. Out of these 17 families, after being contacted by email or phone, 6 families did not respond to the invitation letter, thus resulting in 11 families agreeing to enrolment in the study. The reason for non-participation was time restrictions. No selections were made regarding the inclusion of participants other than having a child with a typical IQ score, aged between 4 and 9 years, and with a diagnosis of DD. Two families decided to participate together as a mother and father, resulting in 13 participants.

This sample consisted of 11 women and 2 men, between 30 and 40 years old, who had a child with DD diagnosis based on DSM criteria. All parents were Belgian, biological parents and identified as full-time caregivers. The variation in duration of the interviews (which were conducted in the parents' home) depended on the fact that sometimes mothers and fathers were both interviewed; thus, they lasted between 45 and $90 \mathrm{~min}$. Only participants and the researcher were present at the time of the interviews. Data were saturated after completing nine interviews; the other three interviews were conducted to confirm the results. No repeat interviews were done. After the interviews were transcribed verbatim and sent to the participants, only one parent added an extra example, as she thought that this would make her point clearer. This information has been added to the data.

Researchers obtained from the parents' demographic information on 11 children. Eight children were boys, 5 out of 11 children had more than one diagnosis, and the remaining 6 were diagnosed with a singular disability but were still in the diagnostic phase, as there was a suspicion of comorbidity. Six children received therapy within public care, while three received therapy from private therapists. One child never received any form of therapy, and 2 out of the 11 children were in special education. In 5 out of the 11 families, there was more than 1 child with a DD. All of the families lived in an urban setting, were middle class and very motivated to have their children succeed. Nine out of 11 families were dual parent families. Two were single mothers. A summary of participants' characteristics can be found in table 2. When parents had more than one child with DD, the parents were asked to focus on the child who was between 4 and 9 years of age. In this sample, the parents had no other children who were between 4 and 9 years of age.

\section{Themes}

The analysis showed reoccurring themes describing parental needs and strategies used. The themes are discussed at length below. Figure 1 represents a graphical presentation of the themes.

\section{Theme 1: parental needs}

Subtheme 1.1: increasing awareness

Parents regularly felt misunderstood due to the unknown nature of DD. As DD are 'invisible' disabilities, the environment did not consider anything 'wrong', resulting in misunderstandings regarding certain (troublesome) behaviour on the part of the child due to the lack of the child's understanding of how to behave or his/her ability to behave in a way that meets the psychosocial expectations of the environment. This lack of understanding, according to the parents' perspective, demonstrated itself in two ways. First, participants felt people were finger pointing at them, blaming parents for not raising their children properly. Second, certain behaviours or problems were downplayed, causing parents to feel frustrated, as it was often not clear to them if it was due to their children's 'negative behaviour' that his or her participation was impeded or because the environment did not give enough support for their participation. Lore explained: 


\begin{tabular}{|c|c|c|c|c|c|c|c|}
\hline Child & Age & Sex & Diagnosis & $\begin{array}{l}\text { IQ of } \\
\text { child }\end{array}$ & Parent interviewed & $\begin{array}{l}\text { Education of interviewed } \\
\text { parent }\end{array}$ & $\begin{array}{l}\text { Education of (ex) } \\
\text { partner }\end{array}$ \\
\hline Daisy & 8 & $\mathrm{~F}$ & ADHD & Normal & $\begin{array}{l}\text { Dad: Lowie } \\
\text { Mom: Sofie }\end{array}$ & Master's degree & Master's degree \\
\hline Lientje & 6 & $\mathrm{~F}$ & ASD & High & $\begin{array}{l}\text { Dad: Bob } \\
\text { Mom: Nele }\end{array}$ & High school diploma & High school diploma \\
\hline Ben & 8 & M & $\begin{array}{l}\text { ASD } \\
\text { ADHD dyslexia }\end{array}$ & High & Mom: Ine & Master's degree & Bachelor's degree \\
\hline Nardas & 7 & M & DCD & Normal & Mom: Anna & Bachelor's degree & Master's degree \\
\hline Miekie & 7 & M & DCD & Normal & Mom: Elke & Bachelor's degree & Bachelor's degree \\
\hline Rudy & 8 & M & $\begin{array}{l}\text { ASD } \\
\text { DCD }\end{array}$ & High & Mom: Lore & High school diploma & High school diploma \\
\hline Brian & 6 & $M$ & DCD & Normal & Mom: Tine & Master's degree & Bachelor's degree \\
\hline Noem & 8 & $\mathrm{~F}$ & $\begin{array}{l}\text { ASD } \\
\text { DCD } \\
\text { ADHD }\end{array}$ & Normal & Mom: Elien & Bachelor's degree & No diploma \\
\hline Bent & 8 & M & $\begin{array}{l}\text { DCD } \\
\text { ASD }\end{array}$ & Normal & Mom: Jana & Bachelor's degree & High school diploma \\
\hline Minnie & 7 & $\mathrm{~F}$ & ADHD & Normal & Mom: Liese & High school diploma & High school diploma \\
\hline Paul & 8 & $M$ & $\begin{array}{l}\text { ASD } \\
\text { ADHD DCD }\end{array}$ & High & Mom: Hilde & Bachelor's degree & High school diploma \\
\hline
\end{tabular}

*Pseudonyms are used for the parents and their children.

ADHD, attention deficit hyperactive disorder; ASD, autism spectrum disorder; DCD, developmental coordination disorder.

"People do not understand ASD. Rudy is way too smart according to them. He always knows what to say and people often respond: But he talks? So he is smart and capable. People think of 'Rain man' when they hear autism."

\section{Subtheme 1.2: ameliorating parental burden}

Parents experienced a high burden, which partly came forth from the environment's lack of understanding. More specifically, they felt that their close network of families, friends as well as therapists did not truly understand that, compared with parents who have children without a disability, it was harder for them to combine everything. Financial, practical and emotional consequences of child caretaking were other factors which led to feelings of parental burden. Participants indicated that
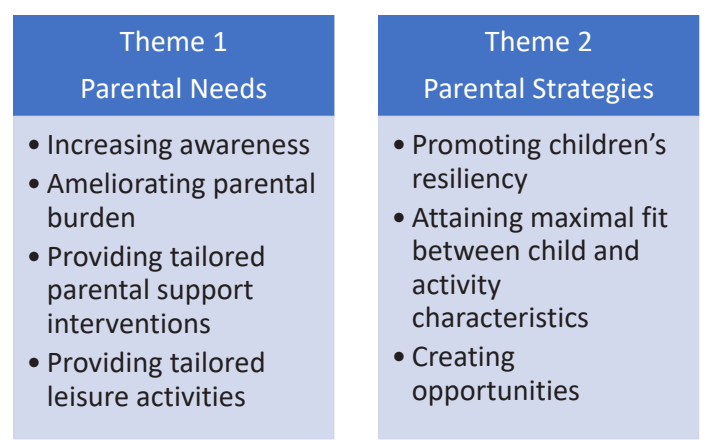

it was hard to combine domestic work while checking on and helping their children. The disability itself and especially the behaviour typically associated with DD such as short attention span or rigidity or clumsiness caused more domestic work and/or stress.

Participants felt increased pressure to combine work and family life in comparison with parents of children without disabilities, as they mentioned that having a child with a disability takes more of their time and energy because a lot of extras need to be done to enable their child's participation (ie, driving to and from therapy sessions, additional work at home). According to Tine, a mother of a boy with DCD, "It is also impossible to always try new things. There are a lot of tools (advice that could help her child). I know that, but I don't have time to try or check them all as I'm already so busy with my daily routine. I already have so much additional work, such as more laundry, washing, repairing clothes... Brian has a torn of pants every week, and he needs more time and assistance. I always have to help him... to go to the bathroom, to verbally help him."

According to the parents, increasing the understanding of others (such as the extended family of the child or healthcare professionals working with the child) of the tension and juggling of multiple responsibilities inherent in raising a child with DD seemed critical to help parents enable their child's participation.

Figure 1 Graphical presentation of the themes. 
Subtheme 1.3: providing tailored parental support interventions Three main reasons for increased feelings of parental burden were mentioned. First, arranging transportation to and from therapy appeared to be very wearisome. It required a lot of planning and time. According to Jana, a single mother of an 8-year-old boy with ASD and DCD, "Driving from and to... That's heavy... Those Wednesday afternoons... We have lost those. There is no time for anything else... I sometimes blame Bent for that." Second, parents were confronted with rotating therapists, which negatively affected their feelings regarding the efficacy of the therapy. Sofie said: "Amy, my daughter already had four to five different therapists in the last two years. This is fatiguing for us as we have to establish a connection with every therapist." With every switch, they felt they had to start all over again, as they lost a confidant and needed to invest extra time and effort, which resulted in feelings of frustration and exhaustion. Third, parents preferred therapy planning/content to be more responsive to the unique needs of each family. Parents wanted therapists who could resist the urge to treat every family the same.

\section{Subtheme 1.4: providing tailored leisure activities}

It was hard to find appropriate leisure activities and/or childcare. Clubs and teams did not offer many leisure activities to children with DD. Many clubs rejected children or asked them to leave after trying a few times. It was difficult to find something that was tailored to their children's needs. Hilde, the mother of Rudy, told us this by saying the following: "We tried to go to the Boy Scouts with our son. But that did not work out really well as he often forgot his tie or did not understand the social rules during the games. We did however have a long conversation with the leaders of the Boy Scouts. This was not successful. And for the Akabe, a group where persons with a disability can join the Boy Scouts, he is too intelligent to be able to join in. That's what's frustrating about a child with a disability. You have to look much harder for something that fits than, for example, children without a disability."

If opportunities were found, they were far away, and thus increased travel time and the burden. Few organisations had properly trained personnel to care adequately for and support these children. The previously mentioned lack of knowledge and training was apparent. Liese stated: "We try to help her to look for a fun activity. She wanted to try soccer but that would be too much for her. It would be too hard and... yeah... a hobby has to be something you perform well at. If you are constantly confronted with negative experiences... and her self-esteem is already not that great... That is why we chose track. But if she had not liked that, we would have searched something else. The experience has to be positive and fun."

\section{Theme 2: parental strategies}

Parents tailored their strategies to a child, activity and environmental levels in order to reach the desired outcome, namely facilitating their child's participation.
These strategies collapsed into three categories: (1) promoting children's participation, (2) attaining a maximal fit between activity requirements and children's capacity, and 3) creating inclusive opportunities.

\section{Subtheme 2.1: promoting children's participation}

Parents coached and educated their children on skills related to skills such as (1) anticipation, (2) putting things into perspective and (3) using metaphors.

Anticipation

Parents reported that they (verbally) prepared their children before an uncommon or difficult activity. They informed their children about the content, location, behavioural expectations of the activity and about what the children could do if something went wrong. Hilde, a mother of three children with DD, when asked what she did to enable her sons' participation said the following: "Yes, it is true that we as a family-unconsciouslyare more structured than a 'typical' family. I have the tendency to automatically tell beforehand what we are going to do. I don't even think about that anymore...."

Putting things into perspective

Whenever participation problems occurred, it was often due to the children's lack of understanding of how to behave in a socially acceptable manner. Parents taught their children how to avoid recurring and/or future negative (social) behaviour by explaining certain actions. Lore, the mother of Rudy, said: "I have to explain to Rudy that changing the rules during a hide and seek game by the other children of his class is not always done because they don't like him. I need to explain to him that other children think differently than him. That for other children, changing rules is fun. That is hard for Rudy as he hates the fact that rules can change just like that." Parents provided a moment to reflect within their daily structure. They offered their children a chance to share their feelings on, thoughts about, and stories of the day in order to release (unnecessary) stress and avoid (bigger) emotional distress. Hilde stated: "I pick Benjamin up after school. When he gets in the car, I ask him how his day was. What was good or fun? What went wrong? Were there fights? And by the time we get home, everything is out of his system. Sometimes I just drive around in the neighborhood until our talk is done. That's important to him."

\section{Using metaphors}

Using metaphors made it easier for young children to understand their behaviour's impact on others. Metaphors framed the children's difficulties and possibilities by using simple and visual language. This helped children to (better) grasp their disability, enabling them to regulate their behaviour and emotions. Parents were creative when coaching their children's negative behaviour that impeded participation. Nele said: "Once I told Lientje that there is a little lion inside of her. The lion stands for difficult behavior and can be aggressive. I told her she is the only one who can arouse this lion. She can make sure 
the beast remains calm. Since then, she is more able to control her anger."

\section{Subtheme 2.2: attaining a maximal fit between children and activity characteristics}

Parents facilitated their children's participation by using two strategies: parental involvement and modifying or adapting activities. Mothers stayed physically close to their children as it offered them opportunities to intervene when necessary. Ine said: "I'm always outside when he plays on the street with kids of the neighbors. I'm hyperaware at that moment... I'm always alert. Ben is not a normal child that plays outside. Something could happen at any moment. He is so unpredictable sometimes." When an activity was difficult or insurmountable, parents adjusted certain elements of it. They looked for alternatives or searched for tools that helped overcome barriers.

When parents noticed that their children felt exhausted, overwhelmed or stressed out, they adjusted daily routines. Outside the home, parents tried to adjust sensory stimuli to facilitate their children's participation. Bob stated: "As a parent you can sense when something is wrong. In that case, we just try to find a solution that works for Lientje. When she had a hard day and it's too busy for her at the dinner table... well... We just provide her with a little table, put it in the corner and give her some 'time alone'. After that, she feels better. Simple."

\section{Subtheme 2.3: creating opportunities}

Parents hoped that by (1) searching for information, (2) using the diagnosis as a tool and (3) modifying the environment, they were able to create inclusive opportunities and awareness.

\section{Search for information}

Parents actively searched for information in order to better support their children. They felt the need to stay up to date with recent methods, resources, adjusted facilities and activities. Self-advocacy groups (on social media) or mainstream media were popular tools to achieve this. Parents often asked other parents in a similar situation or professionals for help in order to obtain new information. Ine told us: "I'm connected to a Facebook group dedicated to ASD and DCD. They frequently post new information on it. And soon I will follow a course on ASD."

\section{Diagnosis as a tool}

Parents indicated they felt 'relieved' when their children got diagnosed. The diagnosis helped most parents to cope with certain child behaviours, as they experienced actions in a different way before and after getting the diagnosis. "Knowing the diagnoses", Anna said, "helped us not to be mad or angry at him as often. Especially my husband is now less irritated when we are at a restaurant and our child is clumsy again. My husband now knows that our son is not doing it on purpose." Participants said they used the diagnosis as a tool to enlarge awareness, hoping this would stimulate inclusion. By sharing their knowledge on DD, parents wanted to adapt environmental expectations, thereby making participation more feasible. They used the diagnosis to explain and as an apology for possible disruptive or obstructive behaviour that interfered with interaction with others. Elke told us: "I use the diagnose as a kind of apology. My son is very forgetful and messy. I often tell teachers or other parents that it's not always his fault. He can't help it... and his dad is also like him."

Modifying the environment

Parents modified their environment in two ways to protect their children from sadness, frustration and anger by (1) avoiding certain activities and therefore deciding not to participate and (2) using energy management strategies.

Parents tended to steer away from activities with high physical expectations or they altered it when possible. Tine, mother of Brian, told us: "Once Brian went ice skating with a friend and his parents. As I knew that this would be difficult, I asked if he could get more help and use a chair on the ice skating ring." They avoided activities with a lot of stimuli, which could be experienced as overwhelming by their children. This was a strategy used by parents, for example, to enhance the family and child's well-being, as this gave their child the opportunity to participate in family routines at home.

They tried to waive activities where their children had to remain focused for a long period of time. Parents stated that they frequently planned moments of rest, as participating was intensive and energy consuming. When not done, disruptive behaviour or signs of fatigue hindered their children's participation.

\section{DISCUSSION AND CONCLUSION}

The first intent of this study was to investigate parental needs while facilitating their children's participation. The second intent was to examine the strategies used by parents. Four parental needs were identified: (1) increasing awareness, (2) ameliorating parental burden, (3) providing tailored interventions and (4) supporting parents in finding tailored leisure activities. Parental strategies were tailored to a child, activity and environmental level. The findings of this study offer additional insights from parents about important aspects of young children's participation and the environment that can inform professionals to ameliorate their interventions. Findings are discussed as they relate to (1) participation-based services, (2) advocacy and (3) increasing awareness.

\section{Participation-based services}

This study extends the current knowledge about the scope of participation-focused strategy used for young children with DD. Results provide further knowledge on core constructs and their interactions as depicted in the fPRC framework and support the use of this coherent conceptual framework by practitioners to design participationfocused practices with families. ${ }^{66}$ 
Similar to other research, ${ }^{16} 315967-69$ findings of this study indicated that parental strategies mainly focused on the modification of the demands of the environment (primarily at the level of the school or community). For example, parents wanted to be more involved in their children's educational and healthcare programme. Hence, professionals should make efforts to jointly set objectives that are identified by children, parents and also professionals. If parental strategies focused on improving the child's behaviour, it was done to manage the complexity of childcare tasks. Similar to our results, studies have revealed that there were associations between young children's behaviour and their adaptation in out-of-home contexts. ${ }^{40-75}$ Parents therefore used adaptive strategies focusing on managing the child's behaviour and the requirements of the environment to enable their child's participation. This finding is congruent with ecocultural theorists' understanding which says that comprehending specific parenting practices that promote children's participation provides a window into parental beliefs and expectations about their children. ${ }^{48}$

This information should then help professionals plan interventions that are culturally relevant and sustainable in a specific context, ${ }^{54} 7374$ especially as there is emerging evidence of the efficacy of compensatory approaches to intervention to improve functional outcomes. ${ }^{22} 75$

The finding that the environment has the potential to serve as a mediator between children's factors and participation has clinical implications. The analysis showed that parental strategies were situated in an attempt to enable a maximal fit between the child's capacity and the activity characteristics, especially as the environment is more amenable to change compared with the children's health conditions and, in some cases, their functioning abilities. As a result, these findings direct professionals' attention towards intervention at the level of the environment and strengthen emerging context-based and participationbased services that focus on changing the environment or tasks, rather than the children's impairments, to improve function and participation. ${ }^{18} 38$

Parents in our study indicated that they wanted to shift away from the more traditional approaches currently still in use in Flemish rehabilitation and early intervention settings. In a traditional approach, professionals directly interact with the children while parents are either not present or observing what the professional is doing. Traditional services are generally child focused and are directly provided by a professional. ${ }^{49}$ Participation-based services reflect the recommended core practices of familycentred care, such as supporting and providing families with knowledge, resources and strategies in such a way that parents may facilitate their children's participation. The purpose of participation-based services is then to promote a child's participation in family and community activities and routines in the actual context of the child and their family.

Parents in our study also revealed that they preferred professionals who would directly teach them how to embed learning strategies within a family's naturally occurring activities and routines. They longed for professionals who were responsive to the family's unique needs when planning parental and child input. For example, by maximising already existing learning opportunities or creating individualised learning opportunities and providing interventions in the actual context where the child and his or her family lives, this would decrease the burden of transportation. ${ }^{57}$ This also fits with the most recent guidelines and recommended practices in early childhood intervention formulated by the Division for Early Childhood. $^{76}$

Professionals should periodically attempt to view the larger picture of parenting children with DD as well as resisting the urge to treat every family the same. ${ }^{77}$ Parents identified the 'larger picture of parenting a child with DD' as a term that indicates all the extras they have that are not visible to professionals, more specifically, juggling all the extras of having a child with DD, such as an increase in domestic chores due to, for instance, the clumsiness of their child, more arguments and issues between siblings, and driving back and forth to healthcare professionals. Similar to other studies, our results revealed that-at least from the perspective of the parents-many professionals were not using participation-based or other routine-based practices yet in day-to-day interactions with children and families. ${ }^{49} 78$ Further research is therefore required to untangle what might influence professionals' practices.

\section{Advocacy}

As our results have highlighted the critical role of the environment in explaining children's participation, they should be of interest to stakeholders, such as policymakers of various organisations (eg, recreational, school, rehabilitation centres). The groups that are interested can enact legislation to remove environmental barriers in order to promote inclusive communities.

Professionals need to think beyond existing structures to pursue opportunities to advocate for inclusive participation. ${ }^{79}$ Examining innovative methods of policy development is warranted when developing policy initiatives to address barriers to participation for young children with DD. The data from this study have the potential to serve as a source of information regarding barriers that require the attention of policymakers.

A potentially fruitful method would be to foster participation as a core task of professionals throughout a community and not always at the level of each individual child. ${ }^{80}$ Moreover, parental burden due to parental stress (caused by a multitude of factors) is not a new phenomenon. It is clear that parental stress is a risk factor for future health problems and that it has a negative impact on long-term interventions. ${ }^{81}$ Professionals should be alert to experiences of parental burden and provide help to reduce it or learn how to cope with it. Researchers should help policymakers to develop policies that focus more on (1) supporting the social network of parents and (2) developing accessible parenting support initiatives alongside 
more targeted forms of parenting support, such as respite care. $^{82}$

\section{Awareness}

A logical approach to facilitate the participation of young children diagnosed with DD is to develop awareness of the importance and benefits of working with families in an ongoing and collaborative manner. The results of this study indicate that professionals should not merely focus on improving children's skills and capacity as the only way to enable their participation. Professionals should also focus on-jointly with parents-advocacy-related strategies at a macro-level, ${ }^{67}$ for example, by campaigning for a larger number of service programmes so that leisure possibilities can be enlarged for this age group. ${ }^{83}$ Moreover, it is important to develop broad macro-level strategies where professionals, parents and parents' associations work together jointly by highlighting the need for inclusive policies.

\section{Limitations and recommendations}

This study focused on parental perspectives only; it is equally important to capture the needs and strategies used by the children themselves. Future studies should identify similarities and differences between the perspectives and needs of the children, their parents and professionals. As only two fathers participated in the study, generalisation of the findings from fathers' perspectives is not feasible. More research should be done on that matter. Even though this study identified the range and scope of strategies parents used to facilitate their child's participation, the effectiveness of those strategies was not assessed. The study drew on a relatively small purposive sample with highly educated parents, a fact which may have had an effect on reported results. It may not be representative of all parents with children with DD. The results are a preliminary effort which can be used as a starting point for further investigation into family experiences related to the participation of young children suffering from DD. The results are not intended to provide a full picture of the phenomena.

\section{CONCLUSION}

This study adds to the emerging body of knowledge that explores parental needs and strategies for enabling their young children with DD to participate. Increasing awareness, ameliorating parental burden, providing tailored interventions and supporting parents to find suitable leisure activities were identified as parental needs. Parents reported a range of strategies aiming at the following: (1) influencing their children's participation by increasing their children's resiliency, (2) attaining a maximal fit between activity requirements and children's capacity, and (3) creating inclusive opportunities and awareness. The results have implications for professionals as this information can be used to inform, refine or tailor participation-based services.
Contributors MC led the writing of the manuscript. MC and FV analysed and interpreted the data. DVdV had substantial contribution to data acquisition, analysis and interpretation. DVdV, AD, HVW and GV had substantial contribution to the study conception and design, data analysis and interpretation. GV and HVW served as external experts to increase the credibility of the findings. All authors revised and approved the final version of the manuscript.

Funding The authors have not declared a specific grant for this research from any funding agency in the public, commercial or not-for-profit sectors.

Competing interests None declared.

Patient consent for publication Not required.

Ethics approval The study was approved by the ethics committee of Ghent University Hospital (B670201837762).

Provenance and peer review Not commissioned; externally peer reviewed.

Data availability statement Data are available upon request from the first author: marieke.coussens@ugent.be.

Supplemental material This content has been supplied by the author(s). It has not been vetted by BMJ Publishing Group Limited (BMJ) and may not have been peer-reviewed. Any opinions or recommendations discussed are solely those of the author(s) and are not endorsed by BMJ. BMJ disclaims all liability and responsibility arising from any reliance placed on the content. Where the content includes any translated material, BMJ does not warrant the accuracy and reliability of the translations (including but not limited to local regulations, clinical guidelines, terminology, drug names and drug dosages), and is not responsible for any error and/or omissions arising from translation and adaptation or otherwise.

Open access This is an open access article distributed in accordance with the Creative Commons Attribution Non Commercial (CC BY-NC 4.0) license, which permits others to distribute, remix, adapt, build upon this work non-commercially, and license their derivative works on different terms, provided the original work is properly cited, appropriate credit is given, any changes made indicated, and the use is non-commercial. See: http://creativecommons.org/licenses/by-nc/4.0/.

\section{ORCID iDs}

Marieke Coussens http://orcid.org/0000-0003-1103-2350

Dominique Van de Velde http://orcid.org/0000-0001-6982-1075

\section{REFERENCES}

1 American Psychiatric Association. Diagnostic and statistical manual for mental disorders. 5th ed. Philadelphia: American Psychiatric Association, 2013.

2 Martin NC, Piek JP, Hay D. DCD and ADHD: a genetic study of their shared aetiology. Hum Mov Sci 2006;25:110-24.

3 Williams J, Holmes C. Children of the 21 st century: slipping through the net. Contemp Nurse 2005;18:57-66.

4 Fliers E, Vermeulen S, Rijsdijk F, et al. Adhd and poor motor performance from a family genetic perspective. J Am Acad Child Adolesc Psychiatry 2009;48:25-34.

5 Visser J. Developmental coordination disorder: a review of research on subtypes and comorbidities. Hum Mov Sci 2003;22:479-93.

6 Rasmussen P, Gillberg C. Natural outcome of ADHD with developmental coordination disorder at age 22 years: a controlled, longitudinal, community-based study. J Am Acad Child Adolesc Psychiatry 2000;39:1424-31.

7 Zwicker JG, Suto M, Harris SR, et al. Developmental coordination disorder is more than a motor problem: children describe the impact of daily struggles on their quality of life. British Journal of Occupational Therapy 2018;81:65-73.

8 Askari S, Anaby D, Bergthorson M, et al. Participation of children and youth with autism spectrum disorder: a scoping review. Rev J Autism Dev Disord 2015;2:103-14.

9 Dahan-Oliel N, Shikako-Thomas K, Majnemer A. Quality of life and leisure participation in children with neurodevelopmental disabilities: a thematic analysis of the literature. Qual Life Res 2012;21:427-39.

10 Coussens M, Van Driessen E, De Baets S, et al. Parents' perspectives on participation of young children with attention deficit hyperactivity disorder, developmental coordination disorder, and/ or autism spectrum disorder: a systematic scoping review. Child Care Health Dev 2020;46:232-243.

11 Coussens M, Destoop B, De Baets S, et al. A qualitative photo elicitation research study to elicit the perception of young children with developmental disabilities such as ADHD and/or DCD and/or ASD on their participation. PLoS One 2020;15:e0229538. 
12 Hodges A, Joosten A, Bourke-Taylor H, et al. School participation: the shared perspectives of parents and educators of primary school students on the autism spectrum. Res Dev Disabil 2020;97:103550.

13 World Health Organisation. International classification of functioning, disability and health. version for children and youth: ICF-CY. Geneva: WHO, 2007.

14 Almqvist L, Uys C, Sandberg A. The concepts of participation, engagement and flow: a matter of creating optimal play experiences. South African Journal of Occupational Therapy 2007;3:8-13.

15 Levasseur M, Richard L, Gauvin L, et al. Inventory and analysis of definitions of social participation found in the aging literature: proposed taxonomy of social activities. Soc Sci Med 2010;71:2141-9.

16 Bedell GM, Khetani MA, Cousins MA, et al. Parent perspectives to inform development of measures of children's participation and environment. Arch Phys Med Rehabil 2011;92:765-73.

17 World Health Organization. International classification of functioning. Disability and Health: ICF, 2001

18 Anaby D, Law M, Coster W, et al. The mediating role of the environment in explaining participation of children and youth with and without disabilities across home, school, and community. Arch Phys Med Rehabil 2014;95:908-17.

19 Imms C, Adair B, Keen D, et al. 'Participation': a systematic review of language, definitions, and constructs used in intervention research with children with disabilities. Dev Med Child Neurol 2016;58:29-38.

20 Imms C, Granlund M, Wilson PH, et al. Participation, both a means and an end: a conceptual analysis of processes and outcomes in childhood disability. Dev Med Child Neurol 2017;59:16-25.

21 978-1-911612-16-2Imms C, Green D, eds. Participation. optimising outcomes in childhood-onset Neurodisability. 1. London: Mac Keith Press, 2020.

22 Adair B, Ullenhag A, Keen D, et al. The effect of interventions aimed at improving participation outcomes for children with disabilities: a systematic review. Dev Med Child Neurol 2015;57:1093-104.

23 Adair B, Ullenhag A, Rosenbaum P, et al. Measures used to quantify participation in childhood disability and their alignment with the family of participation-related constructs: a systematic review. Dev Med Child Neurol 2018:60:1101-16.

24 Imms C, Mathews S, Richmond KN, et al. Optimising leisure participation: a pilot intervention study for adolescents with physical impairments. Disabil Rehabil 2016;38:963-71.

25 Guichard S, Grande C. Differences between pre-school children with and without special educational needs functioning, participation, and environmental barriers at home and in community settings: an international classification of functioning, disability, and health for children and youth approach. Front. Educ. 2018:3:1-11.

26 Hilton CL, Crouch MC, Israel H. Out-of-School participation patterns in children with high-functioning autism spectrum disorders. Am J Occup Ther 2008;62:554-63.

27 Law M, King G, King S, et al. Patterns of participation in recreational and leisure activities among children with complex physical disabilities. Dev Med Child Neurol 2006;48:337-42.

28 King G, Law M, Hurley P, et al. A developmental comparison of the out-of-school Recreation and leisure activity participation of boys and girls with and without physical disabilities. International Journal of Disability, Development and Education 2010;57:77-107.

29 Orlin MN, Palisano RJ, Chiarello LA, et al. Participation in home, extracurricular, and community activities among children and young people with cerebral palsy. Dev Med Child Neurol 2010;52:160-6.

30 Guichard S, Grande C. The role of environment in explaining frequency of participation of pre-school children in home and community activities. Int J of Disabil 2019;65:108-15.

31 Bedell G, Coster W, Law M, et al. Community participation, supports, and barriers of school-age children with and without disabilities. Arch Phys Med Rehabil 2013;94:315-23.

32 Poon KK. The activities and participation of adolescents with autism spectrum disorders in Singapore: findings from an ICF-based instrument. J Intellect Disabil Res 2011;55:790-800.

33 Poon KK, Koh L, Magiati I. Parental perspectives on the importance and likelihood of adult outcomes for children with autism spectrum disorders, intellectual disabilities or multiple disabilities. Res Autism Spectr Disord 2013;7:382-90.

34 Jarus T, Lourie-Gelberg Y, Engel-Yeger B, et al. Participation patterns of school-aged children with and without DCD. Res Dev Disabil 2011;32:1323-31.

35 Jarus T, Anaby D, Bart O, et al. Childhood participation in afterschool activities: what is to be expected? British Journal of Occupational Therapy 2010;73:344-50.

36 Missiuna C, Moll S, King G, et al. Life experiences of young adults who have coordination difficulties. Can J Occup Ther 2008;75:157-66.
37 Axelsson AK. The role of the external personal assistants for children with profound intellectual and multiple disabilities working in the children's home. J Appl Res Intellect Disabil 2015;28:201-11.

38 Albrecht EC, Khetani MA. Environmental impact on young children's participation in home-based activities. Dev Med Child Neurol 2017;59:388-94

39 Di Marino E, Tremblay S, Khetani M, et al. The effect of child, family and environmental factors on the participation of young children with disabilities. Disabil Health J 2018;11:36-42.

40 Lim CY, Law M, Khetani M, et al. Participation in out-of-home environments for young children with and without developmental disabilities. OTJR 2016;36:112-25.

41 Kang L-J, Hsieh M-C, Liao H-F, et al. Environmental barriers to participation of preschool children with and without physical disabilities. Int J Environ Res Public Health 2017;14. doi:10.3390/ ijerph14050518. [Epub ahead of print: 1105 2017].

42 Barron C, Beckett A, Coussens M. Barriers to play and Recreation for children and young people with disabilities. Exploring environmental factors. Berlin: De Gruyter, 2017.

43 Shonkoff JP, Phillips DA, eds. From Neurons to Neighborhoods:The Science of Early Childhood Development. Washington, DC, US: National Academy Press, 2000.

44 Zwicker JG, Harris SR, Klassen AF. Quality of life domains affected in children with developmental coordination disorder: a systematic review. Child Care Health Dev 2013;39:562-80.

45 Missiuna C, Moll S, King S, et al. A trajectory of troubles: parents' impressions of the impact of developmental coordination disorder. Phys Occup Ther Pediatr 2007;27:81-101.

46 Rosenberg L, Jarus T, Bart O. Development and initial validation of the children participation questionnaire (CPQ). Disabil Rehabil 2010;32:1633-44.

47 Mowder BA, Rubinson F, Yasik AE. Evidence-based practice in infant and early childhood psychology. Hoboken: John Wiley \& Sons, 2009.

48 Bronfenbrenner U. Ecological systems theory. Thousand Oaks, CA: Sage Publications Ltd, 2005.

49 Fleming JL, Sawyer LB, Campbell PH. Early intervention providers' perspectives about implementing participation-based practices. Topics Early Child Spec Educ 2011;30:233-44.

50 Mcwilliam R, Casey AM, Sims JL. The Routines-Based interview: a method for gathering information and assessing needs. Infants \& Young Children 2009;22:224-33.

51 Colver AF, Dickinson HO, Parkinson K, et al. Access of children with cerebral palsy to the physical, social and attitudinal environment they need: a cross-sectional European study. Disabil Rehabil 2011;33:28-35.

52 Rosenberg $\mathrm{L}$. The associations between executive functions capacities, performance process skills, and dimensions of participation in activities of daily life among children of elementary school age. Appl Neuropsychol Child 2015;4:148-56.

53 Rosenberg L, Ratzon NZ, Jarus T, et al. Perceived environmental restrictions for the participation of children with mild developmental disabilities. Child Care Health Dev 2012;38:836-43.

54 Benjamin TE, Lucas-Thompson RG, Little LM, et al. Participation in early childhood educational environments for young children with and without developmental disabilities and delays: a mixed methods study. Phys Occup Ther Pediatr 2017:37:87-107.

55 Gorter JW, Stewart D, Woodbury-Smith M. Youth in transition: care, health and development. Child Care Health Dev 2011;37:757-63.

56 Yerxa EJ. Seeking a relevant, ethical, and realistic way of knowing for occupational therapy. Am J Occup Ther 1991;45:199-204.

57 Mandich AD, Polatajko HJ, Rodger S. Rites of passage: understanding participation of children with developmental coordination disorder. Hum Mov Sci 2003;22:583-95.

58 Marshall C, Rossman GB. Designinig qualitative research. 2nd, editor. CA, Thousand Oaks: Sage, 1995.

59 Marshall J, Raffaele Mendez LM, Singleton DL. Barriers and facilitators to parental help-seeking for young children with developmental delays: a qualitative investigation. $J$ Early Interv 2020;42:182-98.

60 Braun V, Clarke V. Using thematic analysis in psychology. Qual Res Psychol 2006;3:77-101.

61 Lichtenberger EO, Kaufman AS. Essential of WPPSI-III assessment. Hoboken: John Wiley \& Sons Inc, 2004.

62 Denzin NK, Lincoln YS. Handbook of qualitative research edition F, editor. Calif, Thousand Oaks: Sage Publications, 2017.

63 Denzin NK, Lincoln YS. The landscape of qualitative research. Los Angeles (Calf): SAGE, 2013

64 Tong A, Sainsbury P, Craig J. Consolidated criteria for reporting qualitative research (COREQ): a 32-item checklist for interviews and focus groups. Int J Qual Health Care 2007:19:349-57. 
65 Richards L. Handling qualitative data: a practical guide. London: Sage Publicaitons, 2005.

66 Kaelin VC, Bosak DL, Villegas VC, et al. Participation-Focused strategy use among caregivers of children receiving early intervention. Am J Occup Ther 2021;75:7501205090p1-7501205090p11.

67 Killeen H, Shahin S, Bedell GM, et al. Supporting the participation of youth with physical disabilities: parents' strategies. British Journal of Occupational Therapy 2019;82:153-61.

68 Law M, Darrah J. Emerging therapy approaches: an emphasis on function. J Child Neurol 2014;29:1101-7.

69 Schwartz C. Parental involvement in residential care and perceptions of their offspring's life satisfaction in residential facilities for adults with intellectual disability. Journal of Intellectual \& Developmental Disability 2005;30:146-55.

70 Khetani MA, Lim HK, Corden ME. Caregiver input to optimize the design of a pediatric care planning guide for rehabilitation: descriptive study. JMIR Rehabil Assist Technol 2017;4:e10.

71 Law MC, Darrah J, Pollock N, et al. Focus on function: a cluster, randomized controlled trial comparing child- versus context-focused intervention for young children with cerebral palsy. Dev Med Child Neurol 2011;53:621-9.

72 McIntyre LL, Blacher J, Baker BL. The transition to school: adaptation in young children with and without intellectual disability. $J$ Intellect Disabil Res 2006;50:349-61.

73 Weisner TS. Ecocultural understanding of children's developmental pathways. Hum Dev 2002:45:275-81.

74 Epley P, Summers J, Turnbull A. Family outcomes of early intervention: families' perception oof need, services and outcomes. Journal of Early Intervention 2011;33:201-19.

75 Anaby DR, Law M, Feldman D, et al. The effectiveness of the pathways and resources for engagement and participation (PreP) intervention: improving participation of adolescents with physical disabilities. Dev Med Child Neurol 2018;60:513-9.

76 Childhood. Dec recommended practices in early intervention/early childhood special education 20142014.

77 Tucker V, Schwartz I. Parents' perspectives of collaboration with school professionals: barriers and facilitators to successful partnerships in planning for students with ASD. School Ment Health 2013;5:3-14.

78 Colyvas JL, Sawyer LB, Campbell PH. Identifying strategies early intervention occupational therapists use to teach caregivers. $A m \mathrm{~J}$ Occup Ther 2010;64:776-85.

79 Ziviani J, Poulsen A, Cuskelly M. Goal setting and motivation in therapy: engaging children and parents. London and Philadelphia: Jessica Kingsley Publishers, 2015.

80 Law M, Petrenchik T, King G, et al. Perceived environmental barriers to recreational, community, and school participation for children and youth with physical disabilities. Arch Phys Med Rehabil 2007;88:1636-42.

81 Ingersoll B, Hambrick DZ. The relationship between the broader autism phenotype, child severity, and stress and depression in parents of children with autism spectrum disorder. Research in Autism Spectrum Disorder 2011;5:337-44.

82 Van Leeuwen K, Rousseau S, Hoppenbrouwers K, et al. Kleine kinderen, kleine zorgen? Ondersteuningsbehoeften van ouders Met zuigelingen in relatie TOT ouder-, kind-en gezinskenmerken. In: Onderzoek SB, editor. Leuven: SWVG, 2010.

83 Fauconnier J, Dickinson HO, Beckung E, et al. Participation in life situations of 8-12 year old children with cerebral palsy: cross sectional European study. BMJ 2009;338:b1458. 